\section{Cardiac considerations in liver transplantation}

\section{ABSTRACT}

Cardiovascular events have a major impact on overall outcomes after liver transplantation. Today's transplant patients are older than those in the past and therefore are more likely to have coexisting cardiac comorbidities. In addition, pathophysiologic effects of advanced liver disease on the circulatory system pose challenges in perioperative management. This review discusses important preoperative, intraoperative, and postoperative cardiac considerations in patients undergoing liver transplant.

\section{KEY POINTS}

The average age of patients undergoing liver transplant has risen over the years, and a greater percentage than in the past now have nonalcoholic steatohepatitis as their underlying diagnosis.

Cardiac evaluation and optimization before liver transplant is crucial to avoid adverse clinical outcomes. This should ideally be done by a dedicated cardiology team with experience and expertise in managing cardiac issues pertinent to this specific population.

Outcomes after liver transplant have improved over time even though the patients are at higher risk.

The clinical outcomes of liver transplant recipients might be further improved preoperatively with standardized cardiac risk-stratification pathways, and perioperatively with evidence-based cardiac clinical care. This is an evolving field, and more research is needed to guide clinical decision-making in several important areas of clinical care.

A ttention to the heart before, during, and after liver transplantation can pay off in terms of better outcomes. This, even though today's liver transplant patients are older than those in the past and more likely to have fatty liver disease as the cause of their liver failure, and even though liver failure, the transplant procedure, and the posttransplant regimen can all predispose to heart disease.

The changing demographics of patients receiving liver transplants and the unique cardiac pathophysiology of patients with advanced liver disease pose significant challenges in managing these patients perioperatively, as we will discuss in the following sections.

doi:10.3949/ccjm.89a.21006
Vikram Sharma, MD, MD(Res)

Department of Hospital Medicine, Cleveland Clinic,

Cleveland, $\mathrm{OH}$; Department of Cardiovascular Medicine, University of lowa, lowa City

Cerise Kleb, MD

Department of Internal Medicine, Cleveland Clinic, Cleveland, $\mathrm{OH}$

Chirag Sheth, MD

Heart, Vascular, and Thoracic Institute, Cleveland Clinic Cleveland, $\mathrm{OH}$

Beni Rai Verma, MD

Department of Hospital Medicine, Cleveland Clinic; Clinical Assistant Professor, Cleveland Clinic Lerner College of Medicine of Case Western Reserve University, Cleveland, $\mathrm{OH}$

Vardhmaan Jain, MD

Department of Internal Medicine, Cleveland Clinic,

Cleveland, $\mathrm{OH}$

Ruchi Sharma, MD, MS

Department of Hospital Medicine, Cleveland Clinic, Cleveland, $\mathrm{OH}$

Parth Parikh, MD

Heart, Vascular, and Thoracic Institute, Cleveland Clinic Clinical Instructor, Cleveland Clinic Lerner College of Medicine of Case Western Reserve University, Cleveland, $\mathrm{OH}$

Jacek Cywinski, MD

Department of General Anaesthesia, Cleveland Clinic; Professor, Cleveland Clinic Lerner College of Medicine of Case Western Reserve University, Cleveland, $\mathrm{OH}$

K. V. Narayanan Menon, MD, FAASLD Medical Director of Liver Transplantation, Digestive Disease and Surgery Institute, Cleveland Clinic; Assistant Professor, Cleveland Clinic Lerner College of Medicine of Case Western Reserve University, Cleveland, $\mathrm{OH}$

Jamak Modaresi Esfeh, MD

Digestive Disease and Surgery Institute, Cleveland Clinic, Cleveland, $\mathrm{OH}$

Bijan Eghtesad, MD

Digestive Disease and Surgery Institute, Cleveland Clinic; Clinical Assistant Professor, Cleveland Clinic Lerner College of Medicine of Case Western Reserve University, Cleveland, $\mathrm{OH}$

Cristiano Quintini, MD

Digestive Disease and Surgery Institute, Cleveland Clinic; Professor, Cleveland Clinic Lerner College of Medicine of Case Western Reserve University, Cleveland, $\mathrm{OH}$

Teresa Diago Uso, MD

Digestive Disease and Surgery Institute, Cleveland Clinic; Assistant Professor, Cleveland Clinic Lerner College of Medicine of Case Western Reserve University, Cleveland, $\mathrm{OH}$

Michael Z. Y. Tong, MD

Heart, Vascular, and Thoracic Institute, Cleveland Clinic; Assistant Professor, Cleveland Clinic Lerner College of Medicine of Case Western Reserve University, Cleveland, $\mathrm{OH}$

Ravi Nair, MD

Heart, Vascular, and Thoracic Institute, Cleveland Clinic: Professor Emeritus, Cleveland Clinic Lerner College of Medicine of Case Western Reserve University, Cleveland, $\mathrm{OH}$

Ajay Bhargava, MD

Heart, Vascular, and Thoracic Institute, Cleveland Clinic: Clinical Assistant Professor, Cleveland Clinic Lerner College of Medicine of Case Western Reserve University, Cleveland, $\mathrm{OH}$

Maan Fares, MD

Heart, Vascular, and Thoracic Institute, Cleveland Clinic

Assistant Professor, Cleveland Clinic Lerner College of

Medicine of Case Western Reserve University, Cleveland, $\mathrm{OH}$ 


\section{OLDER PATIENTS,}

\section{MORE FATTY LIVER DISEASE}

Liver transplant is currently the second most common organ transplant in the United States, after kidney transplant. The number of liver transplants per year has increased greatly over time, from 1,713 in 1988 to 8,906 in $2020 .^{1}$

At the same time the age of patients receiving transplants has also increased. For instance, $476(28 \%)$ of the 1,713 liver transplant recipients in 1988 were age 50 or older, increasing to $6,497(73 \%)$ of 8,906 in $2020 .{ }^{1}$ Survival rates are lower in older patients: $75.0 \%$ at 5 years in those age 35 to $49,70.9 \%$ in those age 50 to 64 , but only $65.9 \%$ in those 65 and older, ${ }^{1}$ likely due to more comorbidities such as coronary artery disease in the older patients.

Another important change in patients receiving liver transplants has been an increase in those with nonalcoholic steatohepatitis as the underlying diagnosis. In 2013, nonalcoholic steatohepatitis was the second most common cause of liver failure in new wait-list registrants for liver transplant, after hepatitis C cirrhosis. ${ }^{2}$

Patients with nonalcoholic steatohepatitis typically have traditional risk factors for coronary artery disease such as diabetes mellitus, obesity, hypertension, and hyperlipidemia, ${ }^{3}$ and thus have a higher risk of coronary artery disease. ${ }^{4}$ After liver transplant, cardiovascular events are much more common in patients with nonalcoholic steatohepatitis than in those with other causes of liver failure. ${ }^{5}$

\section{HEART DISEASE IN LIVER TRANSPLANT RECIPIENTS}

Liver transplant recipients have a higher prevalence of coronary artery disease than in the general population. Other important cardiac conditions to recognize and manage include cirrhotic cardiomyopathy, portopulmonary hypertension, heart failure, and thromboembolism.

\section{Coronary artery disease}

In various studies, ${ }^{6-8}$ the prevalence of coronary artery disease in patients with end-stage liver disease has ranged from $16.2 \%$ to $27 \%$, which is higher than in the general population $(6 \%)^{9}$ and similar to that in patients with diabetes. A recent study found an even higher number $(32.5 \%)$, reflecting the changing profile of patients undergoing liver transplant, with the increasingly older patient population. ${ }^{10}$

The risk of coronary artery disease is particularly high in patients over age 50 and those with coronary risk factors such as diabetes mellitus. ${ }^{7}$ Other important risk factors include hypertension, existing cardiovascular disease, hyperlipidemia, and smoking. Having 3 or more of these risk factors is associated with higher risks of severe coronary artery disease, major adverse cardiovascular events, and death after transplant. ${ }^{11}$ Thus, patients who have multiple risk factors should be thoroughly evaluated for severe coronary artery disease, even if they have no coronary symptoms. ${ }^{12}$

Moreover, older patients currently undergoing liver transplant are also more likely to have concomitant valve disease, which adds further complexity to the management of coronary artery disease in these patients.

\section{Heart failure}

Patients with liver disease can develop both cardiac systolic and diastolic dysfunction over time. Other changes in cardiovascular physiology in end-stage liver disease are listed in Figure 1. These patients also have splanchnic and marked peripheral vasodilation with activation of the renin-angiotensin-aldosterone axis. This results in volume overload and elevated pressures in the right ventricle, pulmonary arteries, and left atrium.

Signs and symptoms of heart failure may be masked in patients with cirrhosis, owing to chronic vasodilation, which reduces cardiac afterload, allowing patients to compensate under resting conditions. However, this cirrhotic cardiomyopathy may be unmasked during conditions of cardiovascular stress, such as during liver transplant. Also, after liver transplant, vascular tone promptly returns to normal, with an ensuing increase in venous return, which can further elevate right-sided pressures and precipitate acute heart failure. ${ }^{13}$ In particular, patients with elevated pulmonary arterial pressure (including those with portopulmonary hypertension), diastolic dysfunction, ${ }^{14}$ and older age are more likely to develop heart failure after transplant. ${ }^{15}$

Thus, it is crucial to carefully optimize he-
Signs and symptoms of heart failure may be masked in patients with cirrhosis 


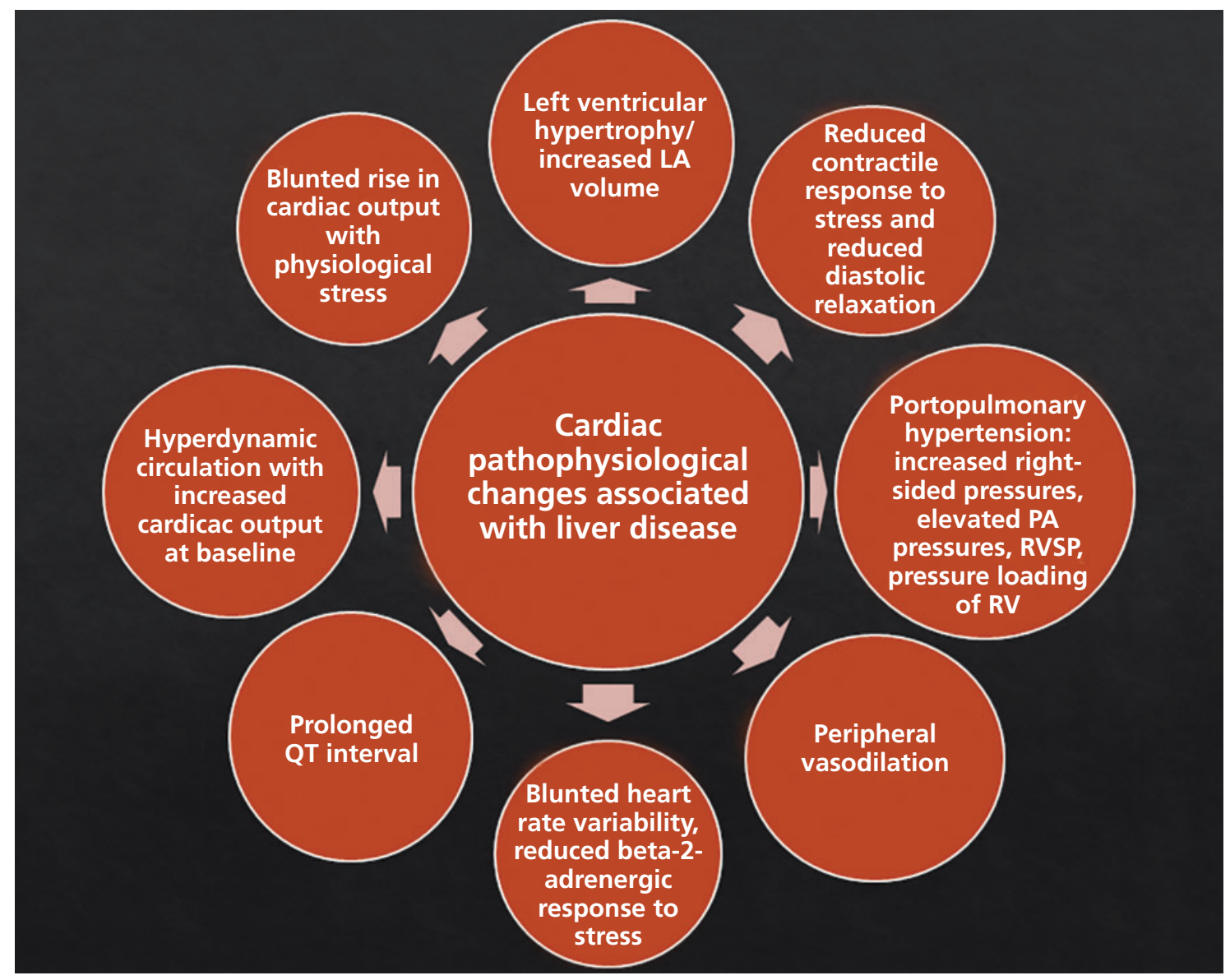

Reducing cardiovascular risk remains one of the most crucial aspects of the pretransplant workup

Figure 1. Cardiovascular pathology in end-stage liver disease.

$\mathrm{LA}=$ left atrial; $\mathrm{PA}=$ pulmonary artery; RV = right ventricle; $\mathrm{RVSP}=$ right ventricular systolic pressure

modynamic variables in the perioperative period, particularly preventing volume overload through careful perioperative fluid management and judicious use of diuretics as needed. Of note, however, cirrhotic cardiomyopathy is reversible, and liver transplant can improve left ventricular thickness, diastolic function, and cardiac systolic response to stress over time. ${ }^{16}$

\section{Other cardiovascular events}

Other cardiovascular events such as perioperative arrhythmias and stroke are also common in liver transplant recipients and contribute to higher morbidity and mortality rates after the procedure. ${ }^{17}$ As a result, liver transplant recipients face a greater risk of cardiovascular events perioperatively, and cardiovascular events are a leading cause of death after liver transplant. ${ }^{18}$ Thus, reducing cardiovascular risk remains a crucial part of the pretrans- plant workup in patients with end-stage liver disease. ${ }^{10,17,19}$ These aspects of perioperative management in liver transplant recipients are discussed further in subsequent sections of this review.

\section{PREOPERATIVE SCREENING FOR HEART DISEASE}

\section{History and physical examination}

The joint 2012 American College of Cardiology and American Heart Association (ACC/ AHA) guidelines for evaluation of cardiac disease in kidney and liver transplant recommend a complete history and physical examination as the first step in evaluating cardiac risk. ${ }^{12}$ This should focus on any active symptoms of heart disease, risk factors for coronary artery disease, and preexisting coronary or cardiovascular conditions. 


\section{Echocardiography for pulmonary hypertension}

The 2012 ACC/AHA guidelines note that it is reasonable for patients to undergo echocardiography to look for pulmonary hypertension and intrapulmonary arteriovenous shunting, ${ }^{12}$ while the 2014 guidelines from the American Association for the Study of Liver Diseases (AASLD) and the American Society of Transplantation (AST) note that it should be done routinely. ${ }^{20}$ Portopulmonary hypertension (concomitant portal and pulmonary hypertension) is found in $5 \%$ to $10 \%$ of patients with chronic liver disease. ${ }^{21}$ Unless patients undergo liver transplant or start on appropriate medical therapy, portopulmonary hypertension carries a very poor prognosis, with 5-year survival rates as low as $14 \% .21,22$

\section{Right heart catheterization}

Right heart catheterization should be performed in patients who have evidence of portopulmonary hypertension on echocardiography, to accurately evaluate the severity and etiology of the pulmonary hypertension (defined as mean pulmonary artery pressure $\geq 25$ $\mathrm{mm} \mathrm{Hg}$, pulmonary capillary wedge pressure $\leq 15 \mathrm{~mm} \mathrm{Hg}$, and pulmonary vascular resistance $>3$ Wood units on right heart catheterization). ${ }^{12,20}$ Furthermore, the guidelines recommend consulting a specialist in pulmonary arterial hypertension and considering vasodilator therapy to manage pulmonary hypertension when appropriate if there is no clear secondary cause such as obstructive sleep apnea or left heart disease.

Liver transplant can be offered to patients with portopulmonary hypertension who respond to medical therapy and have a mean pulmonary artery pressure no greater than 35 $\mathrm{mm} \mathrm{Hg}{ }^{20}$

\section{Cardiopulmonary exercise testing}

Cardiopulmonary exercise testing and a 6- or 3 -minute walk test can provide additional useful prognostic information. ${ }^{20-23}$ In addition, patients being evaluated for liver transplant should have a cardiac workup to see if they may be at increased risk of myocardial ischemia and infarction perioperatively, so that their risk can be optimized.

\section{Cardiac single-photon emission computed tomography}

Cardiac single-photon emission computed tomography (SPECT) has traditionally been a popular choice for the noninvasive ischemic evaluation of patients with a low to moderate risk of cardiovascular events in noncardiac surgery. However, due to the underlying vasodilated state in patients with end-stage liver disease, SPECT can have low sensitivity and specificity as a screening test for coronary artery disease in candidates for liver transplant. ${ }^{12,24,25}$

\section{Stress echocardiography}

The 2013 AASLD/AST guidelines strongly recommend stress echocardiography for cardiac evaluation in liver transplant candidates. ${ }^{20}$ Recognizing that patients with advanced liver disease are less likely to achieve their target heart rate with exercise, the AASLD/AST guidelines recommend pharmacologic stress echocardiography with a vasodilatory agent such as adenosine, dipyridamole, or dobutamine. Cardiac catheterization in cases in which coronary artery disease cannot be excluded confidently with stress testing. ${ }^{20}$

Similarly, the 2012 ACC/AHA statement advocates noninvasive testing for coronary artery disease in candidates for liver or kidney transplant being evaluated for coronary artery disease but does not endorse one particular test. $^{12}$

Dobutamine stress echocardiography remains a commonly used noninvasive tool for preoperative screening for coronary artery disease in liver transplant patients. ${ }^{20}$ However, it has variable sensitivity in these patients and limited ability to identify those at high risk of cardiovascular events and poor outcomes after transplant. ${ }^{25-27}$ In view of its limitations, other imaging modalities such as coronary artery calcium scoring and computed tomographic coronary angiography are being investigated for their utility in the cardiovascular evaluation of liver transplant patients, though their exact role is currently less well defined. ${ }^{28-31}$

\section{Coronary angiography}

Coronary angiography is increasingly being used to screen for cardiovascular disease in liver transplant candidates, particularly in those over age 50 and those who have either known coronary disease or risk factors for it.
Cardiac evaluation and optimization should ideally be done by a dedicated cardiology team 
All patients undergo a comprehensive review of cardiovascular risk factors including a detailed history, physical examination, baseline electrocardiography (ECG), and transthoracic electrocardiography (TTE)

\begin{tabular}{|c|c|c|}
\hline $\begin{array}{l}\qquad \text { Age }<40 \text { years } \\
\text { Proceed to liver transplantation } \\
\text { without further testing if: } \\
\text { - No additional risk factors for coronary } \\
\text { artery disease (CAD) } \\
\text { - No prior known CAD } \\
\text { - No symptoms suggesting CAD } \\
\text { - No worrisome findings on ECG or TTE } \\
\text { Otherwise, perform noninvasive test- } \\
\text { ing for CAD or refer to the heart team, } \\
\text { or both }\end{array}$ & $\begin{array}{l}\text { Age } 40-60 \text { years } \\
\text { Perform noninvasive testing } \\
\text { (eg, dobutamine stress echo- } \\
\text { cardiography, coronary artery } \\
\text { calcium scoring) first if: } \\
\text { - } \quad \text { No additional risk factors for CAD } \\
\text { - No diabetes } \\
\text { - No prior known CAD } \\
\text { - No symptoms suggestive of CAD } \\
\text { - No worrisome findings on ECG } \\
\text { or TTE } \\
\text { Otherwise refer to heart team for } \\
\text { optimization and consideration of } \\
\text { coronary catheterization }\end{array}$ & $\begin{array}{l}\quad \text { Patients at high risk: } \\
\text { - } \quad \text { Age }>60 \text { years } \\
\text { - } \quad \text { History of diabetes mellitus } \\
\text { - } \quad \text { Known CAD } \\
\text { - Impaired cardiac systolic function } \\
\text { - } \quad \text { Equivocal or positive noninvasive } \\
\text { testing } \\
\text { - Symptoms suggesting CAD } \\
\text { - Undergoing concomitant cardiac } \\
\text { All patients need heart-team evalu- } \\
\text { ation for coronary catheterization } \\
\text { unless contraindicated }\end{array}$ \\
\hline
\end{tabular}

Figure 2. Protocol for cardiac evaluation before liver transplantation at Cleveland Clinic.

A dilemma:
dual
antiplatelet
therapy
after stenting
may delay
transplant

Other patients who need an invasive assessment for coronary artery disease include those undergoing concomitant cardiac surgery (such as valve surgery) to accurately study the coronary anatomy so that the need for simultaneous coronary artery bypass grafting can be addressed.

Coronary angiography has become safer for patients undergoing evaluation for liver transplant, especially with increasing use of an approach through the radial artery instead of the femoral artery. This approach greatly reduces the risk of vascular complications. Strict emphasis on minimizing dye load and other precautions such as the use of biplane coronary angiography have also reduced the risk of contrast nephropathy.

\section{Team approach}

Cardiac evaluation and optimization should ideally be done by a dedicated cardiology team with experience and expertise in managing cardiac issues pertinent to this population, ${ }^{12}$ particularly to address the need for coronary revascularization and to optimize cirrhotic cardiomyopathy or any coexisting valve disease before liver transplant and to manage cardiovascular events afterward. Figure 2 summarizes the Cleveland Clinic protocol for pretransplant cardiovascular evaluation of patients with advanced liver disease.

\section{CORONARY REVASCULARIZATION BEFORE LIVER TRANSPLANT}

Patients with preexisting coronary artery disease have a higher risk of perioperative death and postoperative morbidity after liver transplant, and cardiac events are associated with lower survival rates, particularly in older patients. ${ }^{12}$ Yet evidence is still currently lacking regarding which patients would benefit from coronary revascularization before liver transplant.

The 2012 ACC/AHA guidelines state that it is reasonable to consider revascularization for patients who have medically refractory angina before liver transplant, while acknowledging the lack of evidence to support this approach. ${ }^{12}$ Specific indications for revascularization in those without symptoms remain to be established.

Currently, due to the lack of standardized national or international guidelines, the decision about the need for revascularization must 


\section{TABLE 1}

\section{Inclusion and exclusion criteria for combined cardiac surgery and liver transplantation at Cleveland Clinic}

\section{Inclusion criteria}

Severe or complex coronary artery or valve disease not amenable to percutaneous intervention

Contraindication to dual antiplatelet therapy such as need for repeated paracentesis or a noncardiac intervention, or chronic thrombocytopenia

Child-Pugh score $>8$, needing cardiac surgery for cardiovascular optimization but otherwise a candidate for liver transplantation

Patients with a very high Model for End-stage Liver Disease score who cannot wait to complete at least 3 months of dual antiplatelet therapy after a percutaneous intervention before proceeding with liver transplantation

Left ventricular ejection fraction $>55 \%$

\section{Exclusion criteria}

Left ventricular dysfunction

Advanced chronic kidney disease

Unsuitable coronary anatomy

Active infection

Extrahepatic malignancy

Other contraindications to liver transplantation itself, such as evidence of substance abuse, history of nonadherence, and poor social resources

be individualized and based on the experience and prevailing practice in each center. More research and clinical trials are critically needed to guide decision-making in this regard.

In patients who undergo percutaneous coronary intervention before liver transplant, the need for dual antiplatelet therapy necessitates delaying the transplant procedure for at least 3 months. ${ }^{12}$ Further, patients with liver cirrhosis have a higher risk of bleeding complications during dual antiplatelet therapy after percutaneous coronary intervention. However, newergeneration drug-eluting stents may allow for a shorter duration of dual antiplatelet therapy, ${ }^{32,33}$ thereby allowing earlier transplant and reducing bleeding complications after the coronary intervention. ${ }^{34}$ Recent studies have shown that with optimal management of coronary artery disease, clinical outcomes can be similar to those in patients without coronary disease. ${ }^{35}$

\section{VALVE REPAIR BEFORE LIVER TRANSPLANT}

Patients with heart valve abnormalities also need careful hemodynamic optimization peri- operatively, and those with severe valve disease may need valve surgery (if the operative risk is not otherwise prohibitive) or transcatheter intervention as appropriate. Improvements in transcatheter valve therapy in recent years have expanded the indications for these interventions, and outcomes of transcatheter valve therapy are now comparable to those of surgical valve interventions.

\section{COMBINED HEART SURGERY AND LIVER TRANSPLANT}

In some patients, the bleeding risk associated with dual antiplatelet therapy may rule out percutaneous coronary intervention before liver transplant. Furthermore, the coronary anatomy in some patients may be unsuitable for percutaneous intervention, or the coronary disease may be diffuse and therefore impossible to treat with percutaneous intervention.

In addition, some patients may also have coexisting severe valve disease that can only be addressed with cardiac surgery. Such patients have a high risk of perioperative mor-
Liver disease can cause vasodilation, low systemic vascular resistance, and an impaired response to vasoconstrictors 
tality and morbidity if they undergo cardiac surgery or liver transplant alone. For instance, patients with a Child-Pugh score higher than 8 are deemed to have a very high risk of perioperative complications if they undergo cardiac surgery before liver transplant. ${ }^{36}$

In such patients, concomitant cardiac surgery (or cardiac transplant if appropriate and feasible) and liver transplant can be offered, though the risk of adverse events associated with these procedures is higher in patients with advanced liver disease (Child-Pugh class B and C). ${ }^{12,36}$ Patients with a high Model for End-stage Liver Disease score or with a short predicted wait-time for transplant cannot wait to undergo at least 3 months of dual antiplatelet therapy after percutaneous coronary intervention. These patients can be offered simultaneous liver transplant and cardiac surgery, provided they do not have specific contraindications, such as left ventricular dysfunction. ${ }^{36}$

Important contraindications to this combined surgical approach include advanced chronic kidney disease, unfavorable coronary anatomy, active infection, extrahepatic malignancy, evidence of substance abuse,

Acute

left ventricular dysfunction can develop after liver transplant history of nonadherence, and poor social resources.

There are relatively few data in the literature on patients who have undergone simultaneous liver transplant and cardiac surgery. ${ }^{36,37}$ However, we anticipate that with the increasing age at presentation of patients undergoing liver transplant, such combined procedures may become more common.

Table 1 lists the criteria for combined liver and cardiac surgery at Cleveland Clinic.

\section{INTRAOPERATIVE CARDIAC CONSIDERATIONS}

Liver transplant is one of the most demanding surgical procedures and is associated with a significant risk of intraoperative cardiovascular complications and therefore poses intraoperative challenges.

\section{Hemodynamic instability}

A significant number of patients presenting for liver transplant carry hemodynamic sequelae of end-stage liver disease including generalized vasodilation, low systemic vascular resistance, and an impaired vasoconstrictive response to both endogenous and exogenous vasoconstrictors. Cirrhotic cardiomyopathy has been noted in as many as $60 \%$ of patients with cirrhosis. ${ }^{38}$ These patients also have simultaneous central hypovolemia with splanchnic hypervolemia. The combination of acute blood loss, large fluid shifts, and manipulation of the inferior vena cava during surgery can put a significant stress on the cardiovascular system.

Because of these factors, intraoperative hemodynamic instability is common during the dissection phase (due to blood loss) and the hepatic phase (due to obstruction of the inferior vena cava) of liver transplant.

\section{Postreperfusion syndrome}

Immediately after reperfusion of the graft, many patients experience postreperfusion syndrome, defined as a decrease in mean arterial pressure of more than 30\% below the baseline value, lasting at least 1 minute, during the first 5 minutes after reperfusion of the graft. ${ }^{39}$ The reported incidence of postreperfusion syndrome varies widely, ranging from $12 \%$ to $77 \% .{ }^{40} \mathrm{Up}$ to $5 \%$ of patients may experience postreperfusion cardiac arrest. ${ }^{41}$

\section{Other intraoperative cardiovascular complications}

Acute heart failure. Intraoperative heart failure has been reported to occur in up to $3 \%$ of liver transplant procedures, ${ }^{42}$ but that may be an underestimation due to underutilization of intraoperative transesophageal echocardiography. ${ }^{42}$ Transesophageal echocardiography can be safe and useful for intraoperative monitoring of major life-threatening cardiovascular complications during liver transplant surgery, after carefully reviewing the risks and benefits in each patient. ${ }^{43}$

Dynamic left ventricular outflow obstruction can develop intraoperatively due to a combination of decreased venous return (due to bleeding, vena cava obstruction, or volume loss due to the drainage of a large amount of ascites) and hyperdynamic left ventricular function. If untreated, it can lead to severe hypotension and hemodynamic instability. ${ }^{44}$

Takotsubo cardiomyopathy. Stress-induced cardiomyopathy, commonly referred to as takotsubo cardiomyopathy, has been reported perioperatively in the setting of liver trans- 
plant and is most commonly seen in female patients. Risk factors for developing stress-induced cardiomyopathy are poorly understood. Management is similar to that for acute heart failure from other causes, with recovery of systolic function expected in a significant percentage of patients. ${ }^{45}$

Thromboembolism. Right-sided intracardiac thrombosis and pulmonary embolism are other serious thrombotic complications seen during liver transplant and have high mortality rates. Their incidence ranges from $1 \%$ to $6 \% .{ }^{41,46}$ Awareness of these common complications during surgery can lead to their prompt recognition, allowing the anesthesiologist to intervene early and prevent a poor outcome.

\section{CARDIAC CONSIDERATIONS AFTER LIVER TRANSPLANT}

Acute left ventricular dysfunction can develop after liver transplant, particularly if there is evidence of diastolic dysfunction before transplant. ${ }^{14}$ Patients who develop acute left ventricular failure after transplant have a high risk of death and graft failure within the first year. Some patients may recover left ventricular function after liver transplant, though recovery is less likely if they have preexisting diastolic dysfunction. ${ }^{14}$

Heart failure. Patients with evidence of diastolic dysfunction or reduced systolic function before transplant need close postoperative surveillance for signs and symptoms of heart failure. Patients with suspected heart failure or volume overload after transplant should be evaluated with echocardiography, and the cardiology team should be involved early to help manage it.

New coronary artery disease. Liver transplant recipients have an increased risk of developing metabolic syndrome and coronary artery disease after transplant, in particular as a side effect of immunosuppressive regimens. ${ }^{47}$ For instance, steroids, calcineurin inhibitors, and inhibitors of mammalian target of rapamycin are associated with hyperlipidemia, hypertension, obesity, and diabetes, whereas mycophenolate mofetil and azathioprine appear to have no effect on the risk profile for coronary artery disease. ${ }^{17}$

Thus, it is important to focus on preventing coronary artery disease after liver transplant in these patients, aggressively modifying risk factors and carefully selecting the immunosuppressive regimen, especially in those who had a moderate to high risk of coronary artery disease before transplant. ${ }^{19}$ Statins are safe in this patient population. They significantly reduce mortality risk and decrease the risk of graft rejection, yet they remain widely underutilized. ${ }^{48}$

\section{FUTURE DIRECTIONS}

Outcomes after liver transplant, particularly patient and graft survival, have improved with time ${ }^{1}$ despite a higher risk profile in current patients, who are older and have more cardiac comorbidities than those in the past. Considering the major impact that perioperative cardiovascular events have on outcomes, effective cardiac risk stratification and optimization using standardized and evidence-based protocols could further improve the clinical outcomes of liver transplant.

We anticipate that the use of imaging modalities such as computed tomographic coronary calcium scoring and computed tomographic angiography will expand, in addition to the already rising use of coronary angiography and transcatheter valve interventions in high-risk patients.

Next-generation drug-eluting stents and greater use of transcatheter valve interventions may allow for further improvement in the range of options for cardiovascular optimization before transplant.

Growing knowledge about the risk factors for development and progression of heart failure and coronary artery disease after transplant has also clarified the need for thorough clinical monitoring and effective preventive strategies after liver transplant.

More research is needed into these aspects of cardiovascular care, including screening for heart disease and optimizing cardiovascular health before transplant, managing cardiovascular complications during transplant, and preventing cardiovascular disease afterward.

\section{DISCLOSURES}

Dr. Eghtesad has disclosed work as advisor or review panel participant and principal or co-investigator of funded research for Genzyme/Sanofi. Dr. Tong has disclosed consulting, teaching, and speaking for Abbott and Abiomed. The other authors report no relevant financial relationships which, in the context of their contributions, could be perceived as a potential conflict of interest.
Outcomes after liver transplant have improved despite the higher risk profile of current patients 


\section{CARDIAC ISSUES IN LIVER TRANSPLANT}

\section{REFERENCES}

1. US Department of Health and Human Services. Organ Procurement and Transplantation Network. https://optn.transplant.hrsa.gov/ Accessed December 9, 2021.

2. Wong RJ, Aguilar M, Cheung R, et al. Nonalcoholic steatohepatitis is the second leading etiology of liver disease among adults awaiting liver transplantation in the United States. Gastroenterology 2015; 148(3): 547-555. doi:10.1053/j.gastro.2014.11.039

3. Alkhouri N, Tamimi TA, Yerian L, Lopez R, Zein NN, Feldstein AE. The inflamed liver and atherosclerosis: a link between histologic severity of nonalcoholic fatty liver disease and increased cardiovascular risk. Dig Dis Sci 2010; 55(9):2644-2650. doi:10.1007/s10620-009-1075-y

4. Kadayifci A, Tan V, Ursell PC, Merriman RB, Bass NM. Clinical and pathologic risk factors for atherosclerosis in cirrhosis: a comparison between NASH-related cirrhosis and cirrhosis due to other aetiologies. J Hepatol 2008; 49(4):595-599. doi:10.1016/j.jhep.2008.05.024

5. Albeldawi M, Aggarwal A, Madhwal S, et al. Cumulative risk of cardiovascular events after orthotopic liver transplantation. Liver Transpl 2012; 18(3):370-375. doi:10.1002/lt.22468

6. Garg A, Armstrong WF. Echocardiography in liver transplant candidates. JACC Cardiovasc Imaging 2013; 6(1):105-119. doi:10.1016/j.jcmg.2012.11.002

7. Carey WD, Dumot JA, Pimentel RR, et al. The prevalence of coronary artery disease in liver transplant candidates over age 50 . Transplantation 1995; 59(6):859-864. pmid:7701580

8. Lee BC, Li F, Hanje AJ, Mumtaz K, Boudoulas KD, Lilly SM. Effectively screening for coronary artery disease in patients undergoing orthotopic liver transplant evaluation. J Transplant 2016; 2016:7187206. doi:10.1155/2016/7187206

9. Centers for Disease Control and Prevention (CDC). Prevalence of coronary heart disease-United States, 2006-2010. MMWR Morb Mortal Wkly Rep 2011; 60(40):1377-1381. pmid:21993341

10. Patel SS, Lin FP, Rodriguez VA, et al. The relationship between coronary artery disease and cardiovascular events early after liver transplantation. Liver Int 2019; 39(7):1363-1371. doi:10.1111/liv.14092

11. Alexander S, Teshome M, Patel H, Chan EY, Doukky R. The diagnostic and prognostic utility of risk factors defined by the AHAVACCF on the evaluation of cardiac disease in liver transplantation candidates. BMC Cardiovasc Disord 2019; 19(1):102. doi:10.1186/s12872-019-1088-1

12. Lentine KL, Costa SP, Weir MR, et al. Cardiac disease evaluation and management among kidney and liver transplantation candidates: a scientific statement from the American Heart Association and the American College of Cardiology Foundation. J Am Coll Cardiol 2012; 60(5):434-480. doi:10.1016/j.jacc.2012.05.008

13. Hogan BJ, Gonsalkorala E, Heneghan MA. Evaluation of coronary artery disease in potential liver transplant recipients. Liver Transpl 2017 23(3):386-395. doi:10.1002/lt.24679

14. Sonny A, Govindarajan SR, Jaber WA, Cywinski JB. Systolic heart failure after liver transplantation: incidence, predictors, and outcome. Clin Transplant 2018; 32(3):e13199. doi:10.1111/ctr.13199

15. Eimer MJ, Wright JM, Wang EC, et al. Frequency and significance of acute heart failure following liver transplantation. Am J Cardiol 2008; 101(2):242-244. doi:10.1016/j.amjcard.2007.08.056

16. Torregrosa M, Aguadé S, Dos L, et al. Cardiac alterations in cirrhosis: reversibility after liver transplantation. J Hepatol 2005; 42(1):68-74. doi:10.1016/j.jhep.2004.09.008

17. Izzy M, VanWagner LB, Lee SS, Altieri M, Angirekula M, Watt KD. Understanding and managing cardiovascular outcomes in liver transplant recipients. Curr Opin Organ Transplant 2019; 24(2):148-155. doi:10.1097/MOT.0000000000000614

18. Pruthi J, Medkiff KA, Esrason KT, et al. Analysis of causes of death in liver transplant recipients who survived more than 3 years. Liver Transpl 2001; 7(9):811-815. doi:10.1053/jlts.2001.27084

19. D'Avola D, Cuervas-Mons V, Martí J, et al. Cardiovascular morbidity and mortality after liver transplantation: the protective role of mycophenolate mofetil. Liver Transpl 2017; 23(4):498-509. doi:10.1002/lt.24738

20. Martin P, DiMartini A, Feng S, Brown R Jr, Fallon M. Evaluation for liver transplantation in adults: 2013 practice guideline by the American Asso- ciation for the Study of Liver Diseases and the American Society of Transplantation. Hepatology 2014; 59(3):1144-1165. doi:10.1002/hep.26972

21. Bozbas SS, Bozbas H. Portopulmonary hypertension in liver transplant candidates. World J Gastroenterol 2016; 22(6):2024-2029. doi:10.3748/wjg.v22.i6.2024

22. Swanson KL, Wiesner RH, Nyberg SL, Rosen CB, Krowka MJ. Survival in portopulmonary hypertension: Mayo Clinic experience categorized by treatment subgroups. Am J Transplant 2008; 8(11):2445-2453. doi:10.1111/j.1600-6143.2008.02384.x

23. Dharancy S, Lemyze M, Boleslawski E, et al. Impact of impaired aerobic capacity on liver transplant candidates. Transplantation 2008 ; 86(8):1077-1083. doi:10.1097/TP.0b013e318187758b

24. Bhutani S, Tobis J, Gevorgyan R, et al. Accuracy of stress myocardial perfusion imaging to diagnose coronary artery disease in end stage liver disease patients. Am J Cardiol 2013; 111(7):1057-1061. doi:10.1016/j.amjcard.2012.12.023

25. Patel KK, Young L, Carey W, et al. Preoperative dobutamine stress echocardiography in patients undergoing orthotopic liver transplantation. Clin Cardiol 2018; 41(7):931-935. doi:10.1002/clc.22980

26. Harinstein ME, Flaherty JD, Ansari AH, et al. Predictive value of dobutamine stress echocardiography for coronary artery disease detection in liver transplant candidates. Am J Transplant 2008; 8(7):1523-1528. doi:10.1111/j.1600-6143.2008.02276.x

27. Soldera J, Camazzola F, Rodríguez S, Brandão A. Cardiac stress testing and coronary artery disease in liver transplantation candidates: metaanalysis. World J Hepatol 2018; 10(11):877-886. doi:10.4254/wjh.v10.i11.877

28. Kemmer N, Case J, Chandna S, Neff GW. The role of coronary calcium score in the risk assessment of liver transplant candidates. Transplant Proc 2014; 46(1):230-233. doi:10.1016/j.transproceed.2013.09.035

29. Kong YG, Kang JW, Kim YK, et al. Preoperative coronary calcium score is predictive of early postoperative cardiovascular complications in liver transplant recipients. Br J Anaesth 2015; 114(3):437-443. doi:10.1093/bja/aeu384

30. Choi JM, Kong YG, Kang JW, Kim YK. Coronary computed tomography angiography in combination with coronary artery calcium scoring for the preoperative cardiac evaluation of liver transplant recipients. Biomed Res Int 2017; 2017:4081525. doi:10.1155/2017/4081525.

31. Malik MU, Russell SD, Pustavoitau A, et al. The predictors of posttransplant coronary events among liver transplant recipients. Hepatol Int 2016; 10(6):974-982. doi:10.1007/s12072-016-9742-5

32. Levine GN, Bates ER, Bittl JA, et al. 2016 ACC/AHA guideline focused update on duration of dual antiplatelet therapy in patients with coronary artery disease: a report of the American College of Cardiology/American Heart Association Task Force on Clinical Practice Guidelines. J Am Coll Cardiol 2016; 68(10):1082-1115. doi:10.1016/j.jacc.2016.03.513

33. Kirtane AJ, Stoler R, Feldman R, et al. Primary results of the EVOLVE short DAPT study: evaluation of 3-month dual antiplatelet therapy in high bleeding risk patients treated with a bioabsorbable polymer-coated everolimus-eluting stent. Circ Cardiovasc Interv 2021; 14(3):e010144. doi:10.1161/CIRCINTERVENTIONS.120.010144

34. Dalal A. Organ transplantation and drug eluting stents: perioperative challenges. World J Transplant 2016; 6(4):620-631. doi:10.5500/wjt.v6.i4.620

35. Wray C, Scovotti JC, Tobis J, et al. Liver transplantation outcome in patients with angiographically proven coronary artery disease: a multiinstitutional study. Am J Transplant 2013; 13(1):184-191. doi:10.1111/j.1600-6143.2012.04293.x

36. Wood A, Eghtesad B, Menon KVN, et al. Safety and outcomes of combined liver transplantation and cardiac surgery in cirrhosis. Ann Thorac Surg 2021; 111(1):62-68. doi:10.1016/j.athoracsur.2020.04.135

37. Lima B, Nowicki ER, Miller CM, Hashimoto K, Smedira NG, Gonzalez-Stawinski GV. Outcomes of simultaneous liver transplantation and elective cardiac surgical procedures. Ann Thorac Surg 2011; 92(5):1580-1584. doi:10.1016/j.athoracsur.2011.06.056

38. Razpotnik M, Bota S, Wimmer P, et al. The prevalence of cirrhotic cardiomyopathy according to different diagnostic criteria. Liver Int 2021; 41(5):1058-1069. doi:10.1111/liv.14769

39. Aggarwal S, Kang Y, Freeman JA, Fortunato FL, Pinsky MR. Postreperfu- 


\section{SHARMA AND COLLEAGUES}

sion syndrome: cardiovascular collapse following hepatic reperfusion during liver transplantation. Transplant Proc 1987; 19(4 suppl 3):54-55. pmid:3303534

40. Ryu HG, Jung CW, Lee HC, Cho YJ. Epinephrine and phenylephrine pretreatments for preventing postreperfusion syndrome during adult liver transplantation. Liver Transpl 2012; 18(12):1430-1439. doi:10.1002/lt.23511

41. Markin NW, Ringenberg KJ, Kassel CA, Walcutt CR, Chacon MM. 2018 Clinical update in liver transplantation. J Cardiothorac Vasc Anesth 2019; 33(12):3239-3248. doi:10.1053/j.jvca.2019.02.004

42. Mandell MS, Seres T, Lindenfeld J, et al. Risk factors associated with acute heart failure during liver transplant surgery: a case control study. Transplantation 2015; 99(4):873-878. doi:10.1097/TP.0000000000000387

43. De Marchi L, Wang CJ, Skubas NJ, et al. Safety and benefit of transesophageal echocardiography in liver transplant surgery: a position paper from the Society for the Advancement of Transplant Anesthesia (SATA). Liver Transpl 2020; 26(8):1019-1029. doi:10.1002/lt.25800

44. Argalious M, Fares M. Pro: Dynamic LVOT obstruction should be considered an 'expected' finding in patients with end-stage liver disease undergoing dobutamine stress echocardiography in preparation for liver transplantation. J Cardiothorac Vasc Anesth 2017; 31(6):2290-2292. doi:10.1053/j.jvca.2017.04.022

45. Vitin AA, Azamfirei L, Tomescu D. Perioperative stress-induced (takotsubo) cardiomyopathy in liver transplant recipients. J Crit Care Med (Târgu Mureş) 2018; 4(2):56-63. pmid:30581996

46. Shillcutt SK, Ringenberg KJ, Chacon MM, et al. Liver transplantation: intraoperative transesophageal echocardiography findings and relationship to major postoperative adverse cardiac events. J Cardiothorac Vasc Anesth 2016; 30(1):107-114. doi:10.1053/j.jvca.2015.09.009

47. Madhwal S, Atreja A, Albeldawi M, Lopez R, Post A, Costa MA. Is liver transplantation a risk factor for cardiovascular disease? A meta-analysis of observational studies [published correction appears in Liver Transpl 2013; 19(1):113. Albeldawdi, Mazen; corrected to Albeldawi, Mazen]. Liver Transpl 2012; 18(10):1140-1146. doi:10.1002/lt.23508

48. Ho YJ, Koh ASM, Ong ZH, et al. The underutilization, adverse reactions and efficacy of statins after liver transplant: a meta-analysis and systematic review. Transplantology 2021; 2:264-273. doi:10.3390/transplantology2030025

Address: Maan Fares, MD, Heart, Vascular, and Thoracic Institute, J2-4, Cleveland Clinic, 9500 Euclid Avenue, Cleveland, $\mathrm{OH} 44195$;

faresm@ccf.org 